\section{Email Vs. Instagram Recruitment Strategies For Online Survey Research}

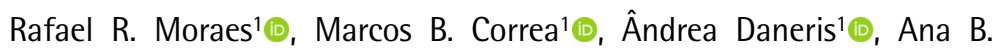
Queiroz ${ }^{1} \mathbb{D}$, João P. Lopes $^{1} \mathbb{D}$, Giana S. Lima ${ }^{1} \mathbb{B}$, Maximiliano S. Cenci ${ }^{1}$, Otávio P. D'Avila ${ }^{1} \mathbb{D}$, Claudio M. Pannuti2 ${ }^{\mathbb{D}}$, Tatiana Pereira-Cenci ${ }^{1} \mathbb{D}$, Flávio F. Demarco ${ }^{1}$ (D)
'School of Dentistry, UFPEL

- Universidade Federal de

Pelotas, Pelotas, RS, Brazil

${ }^{2}$ School of Dentistry, USP - University

of São Paulo, São Paulo, SP, Brazil

Correspondence: Prof. Rafael Moraes, Rua Gonçalves Chaves 457, sala 505, 96015-560 Pelotas, RS, Brasil. Tel: +55-53-3260-2831. e-mail: rafael.moraes@ufpel.edu.br
In this study, we describe a method for reaching a target population (i.e., dentists practicing in Brazil) to engage in survey research using traditional e-mail invites and recruitment campaigns created on Instagram. This study addresses methodological aspects and compares respondents reached by different methods. A pre-tested questionnaire was used and participants were recruited for 10 days via a source list of email addresses and two discrete Instagram organic open campaigns. A total of 3,122 responses were collected: 509 participants were recruited by email (2.1\% response rate) and 2,613 by the two Instagram campaigns ( $20.7 \%$ and $11.7 \%$ conversion rates), respectively. Response/min collection rates in the first $24 \mathrm{~h}$ ranged between 0.23 (email) and 1.09 (first campaign). In total, $98.8 \%$ of all responses were received in the first $48 \mathrm{~h}$ for the different recruitment strategies. There were significant differences for all demographic variables $(p<0.001)$ between email and Instagram respondents, except for sex ( $p=0.37)$. Instagram respondents were slightly older, had more professional experience (years in practice), and a higher graduate education level than email respondents. Moreover, most email and Instagram respondents worked in the public sector and private practice, respectively. Although both strategies could collect responses from all Brazilian regions, email responses were slightly better distributed across the five territorial areas compared to Instagram. This study provides evidence that survey recruitment of a diverse, large population sample using Instagram is feasible. However, combination of email and Instagram recruitment led to a more diverse population and improved response rates.
Key Words: social media, surveys and questionnaires, response collection, demography.

\section{Introduction}

A major challenge in survey research is developing a method for recruiting potential participants that reaches a broad respondent range and allows a sample with diverse characteristics that is representative of the target population. Traditional surveying strategies, including in-person and telephone recruitments, are time-intensive but can yield good response rates (1-4). Recruitment via the Internet became frequent when emails were the most used online media and still remains a popular method. The major drawbacks of email recruitment include the difficulty in gathering updated email addresses (5) and fluctuating response rates $(1,3,4,6)$.

Social networking services are currently used in daily communications and can be considered important learning and collaboration developments in healthcare (7-8). Facebook, YouTube, and Instagram are currently the top three most popular social networks (9). Instagram is a photo- and video-sharing service that allows users to make visual and textual meanings to interact with ambient viewers (10). It is currently the fastest growing social media platform and reached 1 billion monthly active users worldwide in 2020 (9). Instagram is among the most frequently used tools by the World Health Organization and other public health agencies for disseminating visually rich health-related messages $(8,11)$. Current use of Instagram as a research tool can be categorized into educational/ informational purposes and motivational/supportive applications (8).

Facebook has been used in research to reach target populations (2,12-16). Contrastingly, there have been few reports regarding the use of Instagram for the same purpose. A recent study (13) showed that Facebook and Instagram audience-tailored strategies allowed the recruitment of a population characterized as hardto-reach (i.e., LGBT+ young adults). Another study (15) reported that paid advertising on Facebook, Instagram, and Snapchat promoted the recruitment of youths to a prevention campaign. A significant challenge is that website links are not allowed in Instagram posts and comments, which increases the number of steps required for potential participants to reach the online collection tool. However, the homophilic character of online social networks may favorably contribute to their use as recruitment methods since individuals tend to associate, follow, and bond with 
similar individuals (17). Novel online surveying/recruitment strategies are especially important for situations such as the coronavirus disease (COVID-19) pandemic where sanitary measures prevent traditional research approaches. Specifically, the pandemic may facilitate online recruitment since people have been spending more time at home and on social media (18). This research type may be largely used in the next years when there is a risk of a COVID-19 resurgence (19). This is further reinforced by the potential better cost-effectiveness of social media recruitment compared with traditional enrollment methods (16).

The use of social media as a research tool presents new challenges to those already present in traditional surveying strategies, including the expected sociodemographic diversity from different recruitment approaches and the generalizability of research findings $(1,20)$. This study aimed to describe a method for reaching a target population to engage in survey research via traditional e-mail invites combined with a recruitment campaign created on Instagram. Specifically, this study aimed to determine the feasibility of using Instagram to recruit a diverse sample of participants and analyze survey respondents reached by Instagram and email, as well as methodological details related to this study design.

\section{Material and Methods}

To illustrate this methodological paper, an online survey targeting dentists in Brazil is described, with a focus on the recruiting strategy rather than the participants. We have previously attempted to reach dentists working in Brazil via emails sent by regional dental councils with low return rates (6). Therefore, in a recent study addressing the COVID-19 impact on dentistry (21), we prospected to additionally use Instagram to reach our target population since it is among the most popular social networks worldwide. Further, it is widely used by dentists in Brazil, with \#dentistry and \# odontologia (Portuguese for dentistry) having been used in 5.9M and 7.9M posts by November, 2020, respectively. To the best of our knowledge, this was one of the first studies to use Instagram to reach dental healthcare professionals to engage in survey research (21).

\section{Study Design}

Dentists were the target population of the open survey. Brazil has the largest population of dental professionals in the world (22), with more than 348,000 dentists working in the public network and/or in private offices. The study protocol was approved by our institutional review board (\#4.015.536). A 30-item questionnaire (three screens) was developed, pre-tested, and used in a cross-sectional survey. The questionnaire items mainly assessed the impact of COVID-19 on the dental practice routine (21); however, the scope of the present paper does not include COVID-19 and pandemic-related questions. In accordance with open science practices, the research protocol, questionnaire in its original language, databank of responses, and other study-related information have been published in an open platform (doi:10.17605/OSF.IO/DNBGS). The Checklist for Reporting Results of Internet E-Surveys - CHERRIES (23) and article that proposes the SUrvey Reporting GuidelinE - SURGE (24) were consulted for this paper.

\section{Questionnaire Development and Pre-Testing}

The study protocol was detailed in our previous article (21). A self-administered electronic questionnaire was developed based on the inputs of at least 8 researchers in three discrete review rounds. The questionnaire was hosted online on Google Forms (Google Inc., Mountain View, CA, USA) and pre-tested using a sample of 22 verified dentists from different locations in Brazil. The dentists were asked to evaluate clarity, writing style, question sequence, and internal consistency. This allowed the assessment of the reliability and face validity of the tool and items. There were differences in sex, age, working sector, country region, experience, and education levels across the pre-testers to represent the population of dentists in Brazil. The pretesters were first asked to respond to the questionnaire and record the time taken to complete it: the average time \pm standard deviation (SD) was $7 \pm 2 \mathrm{~min}$. In the second series, the pre-testers ranked the clarity of each question using scores between 1 (not clear) and 5 (very clear) on a Likert scale. There was a text box after every question for pre-testers to explain their scores and place comments, critics, and suggestions, including other response options. Questions rated with scores $\leq 3(n=9)$ were discussed by at least three researchers and edited based on the pre-tester comments. The average \pm SD scores were $4.79 \pm 0.10$ and $4.91 \pm 0.11$ for the 9 questions requiring revision and all 30 questions, respectively. The pretest was important to include other response options, which aided in reducing response bias. The questionnaire was reviewed and revised iteratively by the executive group for approval. Pre-testers were excluded from the definitive study.

\section{Questionnaire Content}

The first page of the questionnaire contained the study title and objective, as well as an invitation exclusively for dentists to participate and complete the questionnaire only once. In this open survey, we did not use any method to verify whether the respondents were actually practicing dentists, thus respondents should be considered participants claiming to be dentists. They were informed that their participation was voluntary and not paid; moreover, they were informed regarding the potential risks 
and benefits, as well as were assured that all responses would be treated confidentially and anonymously. In addition, the respondents were asked not to complete the questionnaire if they were not dentists or they had previously responded, which reduced the risk for duplicate answers. No other means to prevent multiple entries were used. The participants were asked to print or save the first page of the questionnaire as a PDF file to retain a copy of the informed consent form. Contact information of the researchers and institutions responsible for the survey was provided. The participant had to click 'Yes' after the question "Do you agree to participate in the study voluntarily?" to access the questionnaire. By clicking 'No', the survey was terminated. The questionnaire contained 30 mandatory close-ended questions; among them, 8 were related to the demographic and professional profile of the respondents and have been addressed in the present paper. The options 'I'd rather not say', 'I don't know how to answer', and 'Does not apply' were available for all questions to avoid response errors and to reduce possible discomfort in answering any question. Open-ended questions were not used to avoid the need for extensive data review, except for the option "other" in 9 questions. The main outcomes were related to the professionals' behavior regarding their practice routines before and during the pandemic; however, aspects regarding the pandemic are beyond the scope of this article.

\section{Participant Recruitment via E-Mail}

The participants were recruited for 10 days. The first strategy for reaching out to the target population was the use of traditional email invites. A source list of 24,126 emails of dentists who mainly work in the public healthcare network was used. An online survey software was used to send the email invites (SurveyMonkey, San Mateo, CA, USA). The email body contained a short text regarding the study objective, average response time, and the university conducting the study. The online software did not allow placement of the Google Form questionnaire link on the email body. Therefore, the participants had to undergo a two-stage process to access it: clicking on the 'begging the questionnaire' button on the email body and then clicking on the 'access the questionnaire' link on a second screen. The first email was sent on May 15, 2020 and a reminder email was sent after five days.

\section{Participant Recruitment via Instagram}

A second recruitment strategy was the creation of a campaign directed to dentists on Instagram. The open campaign was created in Portuguese and restricted to organic reach among Instagram users, that is, there was no paid advertising. The campaign started on May 20, 2020, which was the date the reminder emails were sent. Since the participants were not asked to identify themselves, starting the Instagram campaign later was important to secure an exclusive period for email responses. The campaign indicated that dentists were invited to participate in an online survey regarding the impact of the pandemic on their routine practice. An Instagram professional account was created (@odcovid) with a short username to facilitate search. Ads were created on MS PowerPoint (Fig. 1), exported into PNG image files, and posted on @odcovid feed and stories. In the post captions, we used hashtags related to dentistry and COVID-19 to increase the reach of the target population. The advertisements called for the attention and participation of dentists with brief descriptions of the study objective, average response time, and the university conducting the study; moreover, the questionnaire website link was available on the @odcovid bio page. This was necessary because Instagram does not allow website links in posts or captions. Thus, participants recruited via Instagram were required to complete a two-stage process to access the questionnaire: search for @odcovid profile in the app and click on the weblink available on the bio page. An Instagram bio is the initial screen when one accesses a profile. It is found underneath the username and contains a small summary of the profile, including contact information and a website link.

Moreover, the participating researchers posted the advertisements on their personal Instagram profiles (feed and/or stories) on the day the campaign was started. To expand the promotion, Brazilian dentists with professional Instagram profiles were asked to disseminate the advertisements with survey invitations. We sent messages via Instagram Direct containing the images used in feed and stories posts to dentists who agreed to repost the advertisements. At least 50 Instagram accounts, which were categorized as either micro $(<10,000$ followers) or meso (10,000-1 million) follower scales (25), were asked to repost the first campaign ads. A second Instagram campaign with similar content, but with a slightly different look (Fig. 1C), was created two days later using a similar methodology except for the inclusion of a sentence that asked the audience to help in disseminating the campaign themselves, which could aid in creating snowball sampling in the social network. Different Instagram users (at least 25 dentists from different Brazilian locations) were asked to repost the advertisements during the second campaign.

\section{Sample Selection and Size, Survey Administration,} and Collection of Responses

All dentists practicing in Brazil were eligible for study participation. The pathway to reach the questionnaire differed between the email and Instagram approaches; however, they both involved a two-stage process, as 
aforementioned. Survey administration was the same since both pathways led the respondents to a unique website link. When the participants clicked on the weblinks provided in the email or the Instagram bio page of @odcovid, they accessed the questionnaire in Google Forms. We tested whether the questionnaire could be read well in different computers, tablets, and cell phones prior to the start of the campaign. No randomization of items or questionnaires

\section{A: Ad for Instagram story}
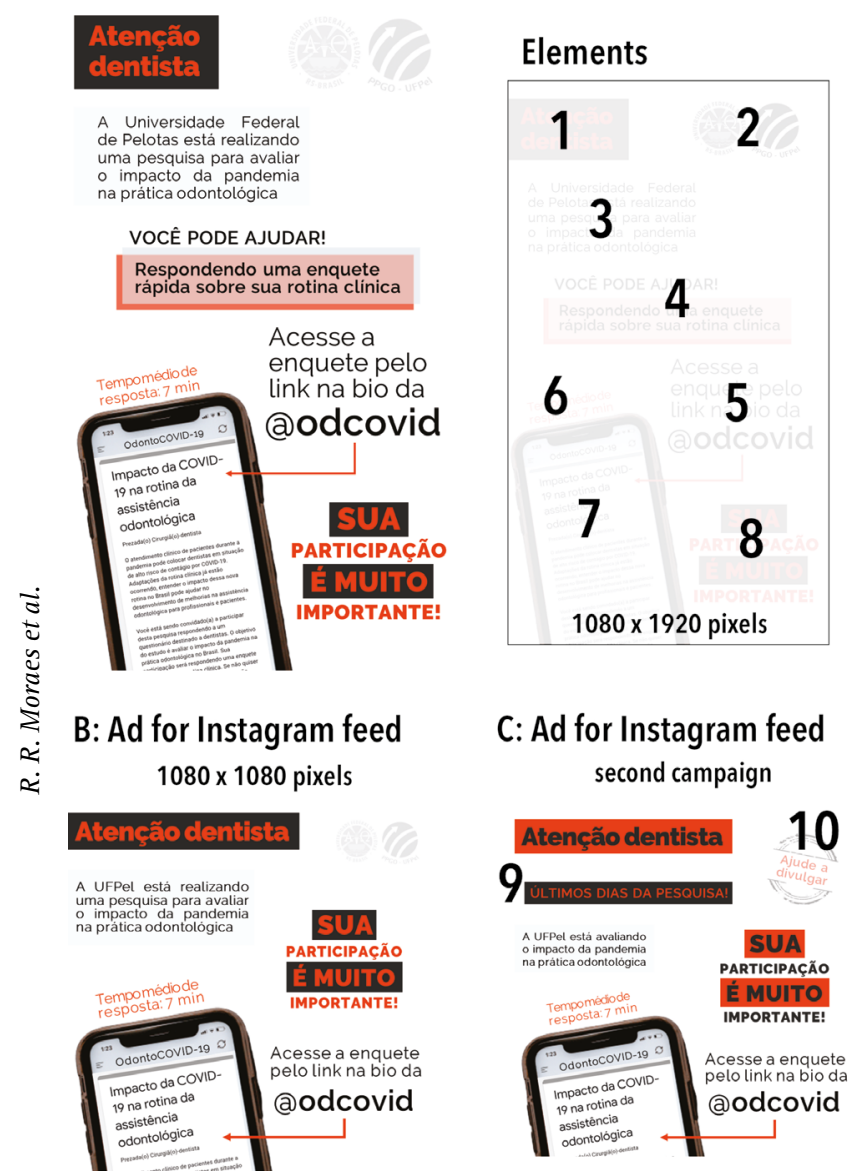

Figure 1. Original ads used to recruit dentists on Instagram with aspect ratios shown in pixels. A: Ad for Instagram story. The marked elements are: 1) mention that the call was for dentists; logos of the institution conducting the study; 3) informative short text indicating the university conducting the research and the study objective; 4) indication that participation would involve response to a questionnaire; 5) information that a website link to the questionnaire was available at @odcovid; 6) average response time (7 min) collected at the pretest; 7) a cell phone containing the first page of the questionnaire was shown; 8) a statement reinforcing that participation was very important. B: Ad for Instagram feed, which had fewer elements than A given its different size and aspect ratio compared with the ad for Instagram story. All elements presented in A were used in B with slight edits, except for element 4. C: Ad with similar content, but a slightly different look, as B, which also indicated that research was in the final days of response collection (9) and asked for help in sharing the survey (10) to aid in creating a snowball-like sampling in the social media. The images were prepared in PowerPoint to have an aesthetically pleasing appearance but to keep a sober tone. Font size varied between 24 (element 6) and 88 (@odcovid in element 5). or adaptive questioning were used. Based on a population of $\sim 348,000$ dentists in Brazil, we estimated that 2,385 responses were required to ensure a 95\% confidence interval with a $2 \%$ margin of error. Responses were collected between May 15 and 24, 2020. The timeframe for response collection was not long since the turbulent pandemic scenario could have led to significant changes in the dentists' behavior in the short term.

\section{Data Analysis}

Partial questionnaire completion was impossible and review was allowed until submitting responses. 'I'd rather not say', 'I don't know how to answer', and 'Does not apply' responses were treated as missing data; therefore, the sample size varied among different responses. No questionnaires submitted with an atypical timestamp were observed. The number of responses and response/ min collection rates in the first $48 \mathrm{~h}$ of recruitment were calculated for each approach. The following numerical outcomes were collected on an Instagram insights dashboard for both campaigns created on @odcovid: likes, direct message shares, comments, unique accounts reached, impressions (i.e., number of times that the post was viewed), website clicks, and story shares. The conversion rates were calculated, that is, the proportion of impressions that led to website clicks. Descriptive statistics were used to identify the frequencies and distributions of variables between the email vs. Instagram respondents. Proportions were compared using chi-square tests. Some data presented here have been previously reported (21).

\section{Results \\ Data on Responses Received Via Different Recruitment Strategies}

A total of 3,122 valid responses were collected over 10 days, with the dates and times of the responses being recorded on Google Forms. A total of 37 participants clicked on the 'no' response, which indicated that they declined to participate after reading the first questionnaire page (1.2\% refusal rate, $98.8 \%$ completion rate). Figure 2 shows the gathering of valid responses over time and important research timepoints. The response collection dynamics may be divided into three main recruitment phases:

Phase 1 (day 1 through 5): In periods A-B shown in Figure 2 , responses were exclusively received via e-mail invites sent on day 1 ; thus, the population in this phase only included email respondents. A total of 509 responses were received over five days, which comprised an email response rate of $2.1 \%$. The number of actual rejections/ losses could not be calculated because we could not estimate the number of dentists who received the email invites or decided not to respond to the questionnaire, as 
well as the number of emails that went to spam folders. Unique site or survey visitors were not registered.

Phase 2 (day 6 through 8): The first Instagram campaign started on day 6 ( $B$ in Fig. 2); subsequently, on the same day, a reminder email was sent to all individuals in the source email list ( $C$ in Fig. 2). A total of 1991 responses were received in this phase. The response rates in Instagram could not be estimated; however, conversion rates were calculated, which may provide an estimation of return rates, as later detailed in this section. Responses received in Phase 2 mainly originated from Instagram, which was indicated by the remarkably higher response number compared with Phase 1. However, we acknowledge that some email responses could have been present. Thus, Phase 2 could be described as a mixed recruitment phase that was largely determined by Instagram respondents.

Phase 3 (day 8 through 10): Two days after starting the second Instagram campaign (D in Fig. 2), collection of responses was terminated. During this period, 622 responses were received (return rates are described below). This phase almost exclusively contained Instagram responses; however, some late email responses could also have been received.
Phase 3 can be described as involving recruitment exclusive via Instagram.

Table 1 presents the number of responses and response/ min collection rates during the first $48 \mathrm{~h}$ of recruitment using different strategies. In the first $24 \mathrm{~h}$ of each phase, 325,1572 , and 557 responses were collected in Phase 1, 2, and 3 , respectively. The response/min collection rates ranged between 0.23 (email) and 1.09 (first Instagram campaign). Between $24 \mathrm{~h}$ and $48 \mathrm{~h}$ of recruitment, responses for email and the first Instagram campaign reduced by $82.5 \%$ and $67.8 \%$, respectively, compared with the first $24 \mathrm{~h}$. The $24-48$ $\mathrm{h}$ response/min rates were lower for email invites than for the first Instagram campaign; however, they were closer to the values for the second Instagram campaign. Based on the number of responses received in the first $48 \mathrm{~h}$ for the three different recruitment phases, the total number of responses was 3086, which translated to $98.8 \%$ of all responses.

Table 2 presents Instagram data insights for the two recruitment campaigns. The number of likes, shares, comments, and unique accounts reached was lower during the second campaign. The conversion rate was $20.7 \%$ and

$11.7 \%$ in the first and second campaigns, respectively. A total of 442 questionnaire website clicks originated from these two Instagram feed posts, which suggested that at least 2171 Instagram respondents accessed the questionnaire by searching@odcovidin the app.

Comparisons of populations among Phases 1, 2, and 3 revealed significant differences for all demographic and work variables $(p<0.001)$ except for sex $(p=0.16)$. Comparison of Phases 2 and 3 with Phase 1 revealed differences only for changes in frequencies. Therefore, since most responses in Phases 2 and 3 were collected via Instagram recruitment, we

Figure 2. Collected survey responses against time (days). Letters A-D indicate different timepoints of email invites and Instagram campaigns. In 10 days, 3,122 valid responses were received.

Table 1. Number of responses and response/min rates during the first $48 \mathrm{~h}$ for the different recruitment approaches $(\mathrm{N}=3,122)$

\begin{tabular}{lllllll}
\hline & \multicolumn{3}{c}{ Responses, $\mathrm{n}$ (\% of total) } & & \multicolumn{2}{c}{ Response/min collection rate } \\
\cline { 2 - 3 } Phase 1: First email invites & First $24 \mathrm{~h}$ & $24-48 \mathrm{~h}$ & Reduction* & & First 24 h & $24-48 \mathrm{~h}$ \\
Phase 2: First Instagram campaign + email reminder & $1,572(10.4)$ & $57(1.8)$ & $82.5 \%$ & 0.23 & 0.04 \\
Phase 3: Second Instagram campaign & $557(17.8)$ & $506(16.2)$ & $67.8 \%$ & & 1.09 & 0.35 \\
\hline
\end{tabular}

*Difference between "first $24 \mathrm{~h}$ " and "24-48 h" periods. 
decided to report the results with consideration of only two distinct populations: email respondents (Phase 1) and Instagram respondents (Phases $2+3$ ).

\section{Overall Characteristics of the Respondents}

Responses were received from all 26 Brazilian states and the federal district. Table 3 presents the demographic and work practice characteristics of the participants who responded to the questionnaire. As aforementioned, the sample size varied among different variables due to missing data. Most responses were received after the first Instagram campaign started (83.7\%). The respondents were mostly females $(74.7 \%)$ and had been in practice for up to 20 years (73.9\%). The mean age \pm SD of the respondents was $38 \pm$ 11 years. The $X$ and $Y$ generations accounted for 93\% of participants. Residency or advanced special training was the most often reported graduate education level (49\%). Meanwhile, $53 \%$ and $36 \%$ of respondents claimed to work mainly in private clinics and the public sector, respectively. Participants from all Brazilian regions responded to the questionnaire with a predominance of responses from the South and Southeast regions (67.4\%).

\section{Email vs. Instagram Populations}

Figure 3 presents a comparison of the frequencies of responses received by email vs. Instagram recruitment strategies. There were significant differences for all variables $(p<0.001)$ except for sex, which was similar between email and Instagram ( $p=0.373$ ). Email respondents were younger and generally had less professional experience (years in practice as dentists) than Instagram respondents. Instagram respondents reported higher levels of graduate education (MSc or PhD degrees) than email respondents, who more often reported not having completed any graduate education. Professionals who claimed to work in the public sector were mainly reached by email; however,

Table 2. Data insights for the posts on Instagram feed* in the discrete campaigns

\begin{tabular}{lcc}
\hline & $\begin{array}{c}\text { First Instagram } \\
\text { campaign }\end{array}$ & $\begin{array}{c}\text { Second Instagram } \\
\text { campaign }\end{array}$ \\
\hline Likes & 244 & 76 \\
Direct message shares & 366 & 146 \\
Comments & 30 & 4 \\
Story shares & 144 & 38 \\
Unique accounts reached & 1426 & 714 \\
Impressions & 1674 & 821 \\
Website clicks & 346 & 96 \\
Conversion rates $^{* * *}$ & $20.7 \%$ & $11.7 \%$ \\
\hline
\end{tabular}

*Data restricted to @odcovid profile. **Number of times that the posts were seen. ${ }^{* * * *}$ Proportion of impressions leading to website clicks. some of the Instagram respondents claimed to be public practicing dentists. The distribution of respondents by territorial areas showed that both email and Instagram could recruit respondents from all regions; however, the combination of these two recruitment strategies improved the distribution of responses across Brazilian regions.

Table 4 presents a comparison of demographic data of verified dentists working in Brazil compared with the distribution of responses according to sex, age, and Brazilian region. Compared with the general dentist population, there was a larger predominance of females among both email and Instagram recruitments. Responses were well distributed by age as compared with the general population, especially for Instagram respondents. In contrast, email responses were slightly better distributed across the five territorial areas than Instagram responses.

\section{Discussion}

This is one of the first studies to use Instagram to reach a target population for engaging in survey research and to compare the characteristics of populations recruited via email vs. Instagram. Generally, Instagram respondents were slightly older, had more professional experience (years in dentistry practice), and a higher graduate education level than email respondents. Moreover, most email and Instagram respondents claimed to work in the public sector and private practice, respectively. Although both strategies could collect responses from all Brazilian regions, email responses were slightly better distributed across the five territorial areas compared to Instagram. Instagram had a higher frequency of respondents from the South, which was the region where the social network campaign started. Therefore, it seems that combining email and Instagram recruitment strategies was important for increasing sample diversity. These findings are important for survey research using social media recruitment, which is a method likely to be more common in the future given the COVID-19 pandemic scenario. A recent study reported that determining the profile of the target sample is important for choosing the online recruitment method (2).

Instagram recruitment collected more than five times the number of responses collected by email. However, one must consider that the number of emails in the list was likely much lower than the number of dentists who potentially saw the Instagram recruitment ads. The second Instagram campaign was less effective than the first one in engaging participants but still yielded a similar response/min collection rate to emails. To explain the relative success of this completely 'organic' campaign in engaging participants to respond to a questionnaire, one should consider different aspects. First, the target population was large: Brazil has the largest population of dentists in the world, who use 
Instagram very often. Second, this was the first campaign on Instagram for dentists, and probably any healthcare area, in Brazil; thus, novelty could have attracted attention. Soon after the campaign was created, a series of similar surveys with dentists, dental students, and other healthcare professionals in Brazil were posted on Instagram. Until November 2020, we were able to count 36 similar recruitment campaigns. Moreover, in May 2020, the COVID-19 epidemic curve showed early signs of escalation and the Brazilian Ministry of Health indicated that dental appointments should be restricted to urgencies. Dentists (and general people) were staying more at home and using social media more often, and thus were more likely to be engaged. The pandemic burden to dental professions might have also favored recruitment since participants felt that they were contributing to their dental sector during difficult times.

The relative success of our recruitment strategy on Instagram could also be attributed to how people interact in social networks. The diffusion of information is largely determined by homophily, that is, a tendency for similar people to be connected $(26,27)$. This means that people interact with other individuals with similar ideologies, backgrounds, behaviors, and/or interests. A recent study showed that introducing a positive algorithmic bias could not stop online segregation in social networking (28). Targeting a specific population has been reported as important for increasing e-mail survey response rates (5). However, recruiters might have an additional role in online social media surveys. Since dental professionals posted the ads with dentists as targets, the connections
Respondents by sex, \%

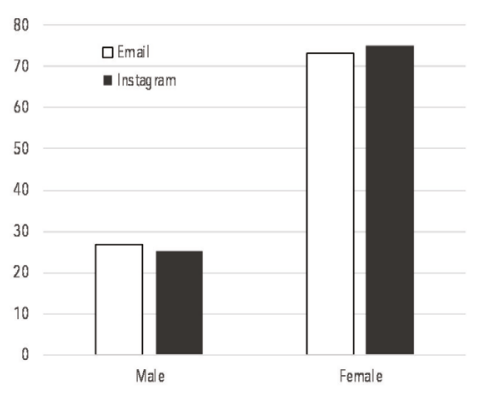

Respondents by experience, $\%$

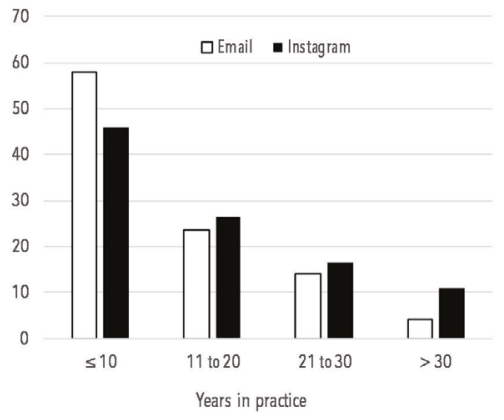

Respondents by practice sector, \%

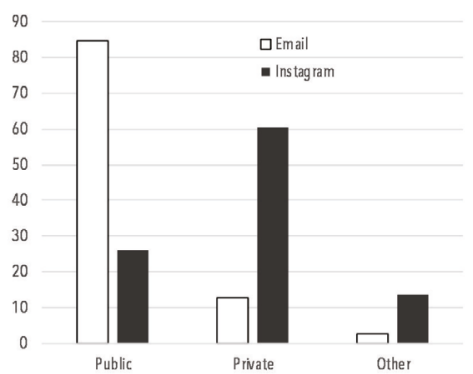

Respondents by age, \%

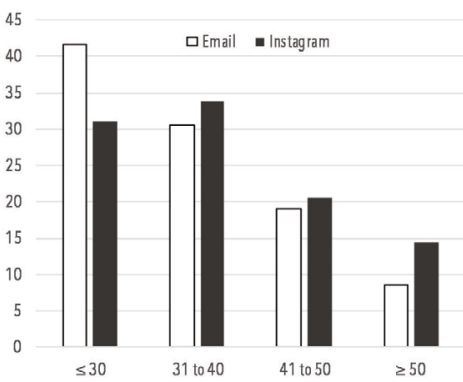

Figure 3. Frequencies of responses received by different recruitment strategies: email vs. Instagram. There were no significant differences in sex between populations recruited by different strategies $(p=0.37)$, whereas all other variables were significantly different between email and Instagram respondents ( $\mathrm{p} \leq 0.001)$.

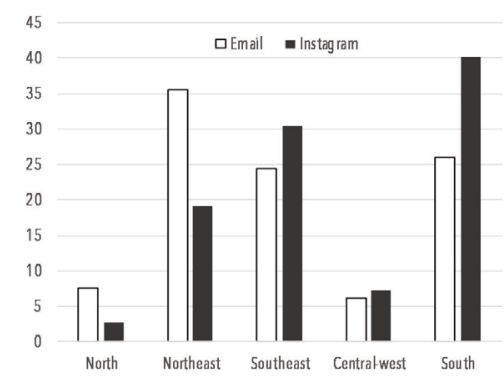

were probably well established given the social and work similarities between recruiters and participants. Social media networking is also driven by the building of reputation, social capital, reciprocity, altruism, and trust (29), which likely breeds more social connections than email invites. Furthermore, these aspects may explain why more Instagram responses were received by participants from the region where the survey began. In addition, the present results are suggestive of the importance of reposts by users from different regions in promotions across large territorial areas, at least in cases where organic reach is 
used for recruitment. This could be seen as a similar approach of snowball sampling, with the difference that social media reposting is not actually a chain referral sampling where one names another potential survey participant taking into consideration similar characteristics that they share. In addition, it should be kept in mind that each particular survey will have its own singularities, methodological nature and focus and may be associated with different challenges and constraints in recruiting individuals that should be considered beforehand (30).

Another relevant finding was that $98.8 \%$ of all responses were gathered in the first 48 $\mathrm{h}$ after initiation of each recruitment strategy, that is, after the first emails were sent or the discrete Instagram campaigns were created. This suggests that leaving an online questionnaire open for longer than two days may not greatly benefit participant recruitment. This is more likely the case for Instagram, where posts have a limited diffusion time; however, email responses were also concentrated within the first few days. Therefore, sending email reminders or reposting ads on social media is encouraged after 48 h. A shortcoming of Instagram campaigns is that response rates cannot be calculated. An alternative is to calculate the conversion rates (Table 2). Assuming that all website clicks at the @odcovid bio page link led to a valid response, only $16.9 \%$ of respondents would have been recruited by the ads posted by @odcovid. Although we could not calculate numbers, the campaigns could have reached a very large population, which allowed recruitment of the remaining 83.1\% of the respondents. Since website clicks do not necessarily lead to survey responses, it is possible that the proportion of respondents recruited by reposts was even higher. This finding confirms the importance of other Instagram users reposting advertisements. Although the questionnaire link was only available on Instagram, the participants may have sent the link to colleagues in other ways, for example, direct messages on Instagram or other social media. Therefore, for surveys recruiting participants through open social media campaigns, researchers are encouraged to include a question in the questionnaire regarding how the respondents became aware of the recruitment.

Notably, email respondents were younger and had lower graduate education levels compared with Instagram respondents. There is a need for further studies to confirm these findings and identify the factors underlying these
Table 3. Demographic and work practice characteristics of the respondents $(\mathrm{N}=3,122)$

\begin{tabular}{lccc}
\hline Variable/category & $\mathrm{n}^{*}$ & $\%$ & $95 \% \mathrm{CI}$ \\
\hline Recruitment method & 3122 & & \\
Email & 509 & 16.3 & $15.0 ; 17.6$ \\
Instagram & 2613 & 83.7 & $82.4 ; 85.0$ \\
Sex & 3,116 & & \\
Male & 790 & 25.4 & $23.9 ; 26.2$ \\
Female & 2,326 & 74.7 & $73.1 ; 76.2$ \\
Generation & 3,121 & & \\
Baby boomers & 227 & 7.3 & $6.4 ; 8.3$ \\
X & 1,311 & 42.0 & $40.3 ; 43.7$ \\
Y & 1,593 & 50.7 & $48.9 ; 52.5$ \\
Years in practice & 3,121 & & \\
$\leq 10$ & 1,496 & 47.9 & $46.2 ; 49.7$ \\
11-20 & 812 & 26.0 & $24.5 ; 27.6$ \\
21-30 & 501 & 16.1 & $14.8 ; 17.4$ \\
>30 & 312 & 10.0 & $9.0 ; 11.1$ \\
Graduate education & 3,121 & & \\
None & 758 & 24.3 & $22.8 ; 25.8$ \\
Residency or advanced special training & 1,530 & 49.0 & $47.3 ; 50.8$ \\
MSc or PhD & 833 & 26.7 & $25.2 ; 28.3$ \\
Main practice sector & 3,051 & & \\
Public & 1,091 & 35.8 & $34.1 ; 37.5$ \\
Private & 1,601 & 52.5 & $50.7 ; 54.2$ \\
Other & 359 & 11.8 & $10.7 ; 13.0$ \\
Brazilian region & 3,122 & & \\
South & 1,183 & 37.8 & $36.2 ; 39.6$ \\
Southeast & 923 & 29.6 & $28.0 ; 31.2$ \\
Central-west & 7.1 & $6.2 ; 8.0$ \\
Northeast & 21.9 & $20.4 ; 23.3$ \\
North & 3.6 & $3.0 ; 4.3$ \\
\hline
\end{tabular}

"Varies from total $\mathrm{N}$ because of missing data for different questions. CI: confidence interval. results. A study in the same region reported that Facebook was the most effective method for recruiting young adults (2). Our results could have been influenced by the characteristics of the population in the convenience email sample used as a source list. For example, a higher prevalence of less experienced dentists could be a factor. Moreover, the respondents' age and familiarity with mobile tools could affect their readiness to check emails and affect response rates since younger people may own and use more cell phones than older people who are relatively passive cell phone users. However, in the present study, both recruitment methods were performed online. In addition, a previous study reported no major differences between older and younger users when physically interacting with digital assistants to complete tasks, including pressing buttons, viewing icons, recording messages, and scanning 
Table 4. Distribution of verified dentists working in Brazil by sex, age, and region (\%) compared with the survey participants recruited by different strategies

\begin{tabular}{lccc}
\hline \multirow{2}{*}{$\begin{array}{l}\text { Variable } \\
\text { category }\end{array}$} & $\begin{array}{c}\text { Dentists working } \\
\text { in Brazil* }\end{array}$ & \multicolumn{2}{c}{ Survey respondents } \\
\cline { 3 - 4 } Sex & & Email & Instagram \\
\hline Male & 43.9 & 26.9 & 25.1 \\
Female & 56.1 & 73.1 & 75.0 \\
\hline Age & & & \\
\hline s30 & 25.2 & 41.6 & 31.0 \\
$31-40$ & 32.2 & 30.6 & 33.9 \\
$41-50$ & 23.6 & 19.1 & 20.1 \\
$51-60$ & 14.1 & 8.1 & 10.3 \\
$>60$ & 4.9 & 0.6 & 4.1 \\
\hline Brazilian & & & \\
region & & 26.0 & 40.2 \\
\hline South & 16.1 & 24.4 & 30.6 \\
Southeast & 52.8 & 6.3 & 7.2 \\
Central-west & 8.8 & 35.6 & 19.2 \\
Northeast & 16.6 & 7.7 & 2.8 \\
North & 5.7 & & \\
\hline
\end{tabular}

*Data obtained from official reports $(22,32)$.

bar codes (31).

In surveys, it might be important to determine whether the sampling method can recruit a population that is representative of the target population. In the present study, representativeness may not be a factor since the objective was to discuss methodological aspects and compare respondent samples. However, data shown in Table 4 provide insights regarding whether the respondents recruited by email and Instagram show correspondence with the general population of verified dentists in Brazil. There were relative similarities between the characteristics of the general practitioners and those of the samples, apart from the aforementioned younger age and less experience among the email respondents (32). Notably, there was a higher response rate among Instagram respondents from Southern Brazil, which differed with the general distribution of dentists. The use of social media campaigns for survey recruitment seems powerful; however, the potential sampling bias should not be underestimated (20); specifically, with respect to collecting more responses from regions near where the campaign began. Therefore, there is a need to determine the means for improving recruitment methods targeting respondents from far regions.

The combination of email and Instagram recruitment seemed to lead to a more diverse population and improve response rates, which is consistent with previous studies involving a combination of different recruitment methods $(1-3,33)$. However, the present study has limitations that should be considered, including the fact that the original survey was not designed specifically to compare participants recruited by different approaches. Another limitation is that the survey method used here was not able to confirm whether the respondents were actually dental professionals, although this seem to be a minor issue with regard to the purpose of this article. Finally, the present study did not assess the reasons for survey participation based on the different types of recruitment approaches, which could be a subject for future research on the topic. In the present study, email and Instagram recruitments followed a very similar approach; however, the emails only had text and lacked pictures, which may lead to differences in communication channels and influence response rates (34). In addition, social media posts might be seen multiple times by participants; contrastingly, although emails are an exclusive invitation, they may not be seen as often. However, these differences between email and Instagram are not expected to introduce measurement differences similar to those observed between face-to-face and internet surveys where the presence or lack of personal contact, as well as the associated social factors, may lead to distinct answer patterns (35). To improve recruitment, other ways to motivate participants may be used, including giveaways and monetary incentives $(31,36)$. The effect of paid advertising on recruitment could also be investigated since social media organic reach is likely to continue shrinking given that social networks are placing strategies for monetizing platform investments.

In conclusion, the present study provides evidence that survey recruitment of a large, diverse population sample using Instagram is feasible and that effective recruitment can be done in the short term. However, using Instagram to engage participants in survey research is challenging and has limitations that warrant further investigation. This article also details how Instagram ads were created and a snowball-like sampling was achieved in this social network service by reposts from users located across different regions. Although the cost-effectiveness of social media campaigns is attractive and using Instagram could recruit at least five times the number of participants recruited by email, our findings suggest that combining email and Instagram recruitment can lead to a more diverse population and improve response rates. In addition, it was shown that the first $48 \mathrm{~h}$ of recruitment are decisive in either recruitment methods.

\section{Resumo}

Neste estudo, descrevemos um método para atingir uma populaçãoalvo (dentistas atuando no Brasil) para se engajar em pesquisa do tipo enquete (survey) utilizando convites tradicionais por e-mail e campanhas de recrutamento criadas no Instagram. Este estudo aborda aspectos metodológicos e compara as pessoas entrevistadas alcançadas por diferentes 
métodos. Foi utilizado um questionário pré-testado e os(as) participantes foram recrutados(as) por 10 dias por meio de uma lista de endereços de e-mail e duas campanhas abertas orgânicas independentes no Instagram. Foram coletadas 3122 respostas: 509 participantes foram recrutados(as) por e-mail (taxa de resposta 2,1\%) e 2613 pelas duas campanhas do Instagram (taxas de conversão 20,7\% e 11,7\%), respectivamente. As taxas de coleta de resposta/min nas primeiras $24 \mathrm{~h}$ variaram entre 0,23 (e-mail) e 1,09 (primeira campanha). No total, $98,8 \%$ das respostas foram recebidas nas primeiras $48 \mathrm{~h}$ para as diferentes estratégias de recrutamento. Houve diferenças significativas para todas as variáveis demográficas $(p<0,001)$ entre recrutados(as) por e-mail e Instagram, com exceção de sexo $(p=0,37)$. As pessoas recrutadas via Instagram eram um pouco mais velhas, tinham mais experiência profissional (anos na prática) e nivel de pós-graduação superior às entrevistadas por e-mail. Além disso, a maioria dos entrevistados por e-mail e Instagram trabalhava no setor público e na prática privada, respectivamente. Embora ambas estratégias tenham sido capazes de coletar respostas de todas as regiões brasileiras, as respostas por e-mail foram ligeiramente melhor distribuidas nas cinco áreas territoriais em comparação ao Instagram. Este estudo fornece evidências de que o recrutamento de uma amostra de população diversificada e grande usando o Instagram é viável. No entanto, a combinação de e-mail e Instagram no recrutamento levou a uma população mais diversificada e melhores taxas de resposta.

\section{Acknowledgements}

We thank all persons who helped to disseminate the campaign on Instagram and respondents who volunteered to participate. This work was supported by Fundação de Amparo à Pesquisa do Estado do Rio Grande do Sul (FAPERGS), Brazil under Grant PRONEX 16/2551-0000471-4; Coordenação de Aperfeiçoamento de Pessoal de Nivel Superior (CAPES),

$\vec{\nabla}$ Brazil under Grants Finance Code 001, PROCAD 3001/2014, and PRINT ¿ 88881.309861/2018-01. The sponsors had no role in study design, collection, analysis or interpretation of data, writing the paper, or decision to submit for publication.

\section{References}

1. Blumenberg C, Barros AJ. Response rate differences between web and alternative data collection methods for public health research: a systematic review of the literature. Int J Public Health 2018; 63:765773.

2. Blumenberg $C$, Menezes $A M B$, Gonçalves $H$, Assunção $M C F$, Wehrmeister $\mathrm{FC}$, Barros AJ. How different online recruitment methods impact on recruitment rates for the web-based coortesnaweb project: a randomised trial. BMC Med Res Methodol 2019;19:127.

3. Dillman DA, Phelps G, Tortora R, Swift K, Kohrell J, Berck J, et al. Response rate and measurement differences in mixed-mode surveys using mail, telephone, interactive voice response (IVR) and the Internet. Soc Sci Res 2009;38:1-18.

4. Garcia I, Portugal C, Chu LH, Kawatkar AA. Response rates of three modes of survey administration and survey preferences of rheumatoid arthritis patients. Arthritis Care Res 2014;66:364-370.

5. Jackson A, DeCormier R. E-mail survey response rates: targeting increases response. Marketing Intell Plann 1999;17:135-139.

6. Gonçalves AP, Correa MB, Nahsan FPS, Soares CJ, Moraes RR. Use of scientific evidence by dentists in Brazil: Room for improving the evidence-based practice. PLoS One 2018;13:e0203284.

7. Abbasi RA, Maqbool O, Mushtaq M, Aljohani NR, Daud A, Alowibdi JS, et al. Saving lives using social media: Analysis of the role of twitter for personal blood donation requests and dissemination. Telemat Informat 2018;35:892-912.

8. Kamel Boulos MN, Giustini DM, Wheeler S. Instagram and WhatsApp in health and healthcare: An overview. Future Internet 2016,8:37.

9. Dreamgrow. Top 15 most popular social networking sites and apps [accessed 2020 November 24], 2020. <https://www.dreamgrow.com/ top-15-most-popular-social-networking-sites/>

10. Zappavigna M. Social media photography: construing subjectivity in Instagram images. Vis Communic 2016;15:271-292.
11. Guidry JP, Jin $Y$, Orr CA, Messner M, Meganck S. Ebola on Instagram and Twitter: How health organizations address the health crisis in their social media engagement. Public Relat Rev 2017;43:477-486.

12. Amon KL, Campbell AJ, Hawke C, Steinbeck K. Facebook as a recruitment tool for adolescent health research: a systematic review. Acad Pediatr 2014;14:439-447.

13. Guillory J, Wiant KF, Farrelly M, Fiacco L, Alam I, Hoffman L, et al. Recruiting hard-to-reach populations for survey research: Using Facebook and Instagram advertisements and in-person intercept in LGBT bars and nightclubs to recruit LGBT young adults. J Med Internet Res 2018;20:e197.

14. Park BK, Calamaro C. A systematic review of social networking sites: innovative platforms for health research targeting adolescents and young adults. J Nurs Scholarship 2013;45:256-264.

15. Rait MA, Prochaska JJ, Rubinstein ML. Recruitment of adolescents for a smoking study: use of traditional strategies and social media. Transl Behav Med 2015:5:254-259.

16. Topolovec-Vranic J, Natarajan K. The use of social media in recruitment for medical research studies: a scoping review. J Med Internet Res 2016;18:e286

17. Yavas M, Yücel G. Impact of homophily on diffusion dynamics over social networks. Soc Sci Comput Rev 2014;32:354-372.

18. Faroog A, Laato $S$, Islam AK. Impact of online information on selfisolation intention during the COVID-19 pandemic: Cross-sectional study. J Med Internet Res 2020;22:e19128.

19. Kissler SM, Tedijanto C, Goldstein E, Grad YH, Lipsitch M. Projecting the transmission dynamics of SARS-CoV-2 through the postpandemic period. Science 2020;368:860-868.

20. Heerman WJ, Jackson N, Roumie CL, Harris PA, Rosenbloom ST, Pulley $J$, et al. Recruitment methods for survey research: Findings from the Mid-South Clinical Data Research Network. Contemp Clin Trials 2017:62:50-55.

21. Moraes RR, Correa MA, Queiroz AB, Daneris A, Lopes JP, Pereira-Cenci T et al. COVID-19 challenges to dentistry in the new pandemic epicenter: Brazil. PLoS One 2020;15:e0242251.

22. Federal Council of Dentistry (CFO), Brazil. Registered professionals and entities. [accessed 2020 November 24], 2020. <http://website.cfo.org. $\mathrm{br} /$ profissionais-cadastrados>

23. Eysenbach G. Improving the quality of Web surveys: The Checklist for Reporting Results of Internet E-Surveys (CHERRIES). J Med Internet Res 2004;6:e34.

24. Grimshaw J. SURGE (The SUrvey Reporting GuidelinE). In: Moher D, Altman DG, Schulz KF, Simera I \& Wager E, editors. Guidelines for reporting health research: A user's manual. 2014 (1st ed), Hoboken (NJ): John Wiley \&t Sons;206-213.

25. Boerman SC. The effects of the standardized Instagram disclosure for micro- and meso-influencers. Comput Hum Behav 2020;103:199-207.

26. Choudhury MD, Sundaram H, John A, Seligmann DD, Kelliher A. "Birds of a Feather": Does user homophily impact information diffusion in social media? arXiv 2010:1006.1702 2010;1-31.

27. McPherson M, Smith-Lovin L, Cook JM. Birds of a feather: Homophily in social networks. Annu Rev Sociol 2001;27:415-444.

28. Blex C, Yasseri T. Positive algorithmic bias cannot stop fragmentation in homophilic social networks. arXiv 2020;2001.02878v1;1-25.

29. Chang $H H$, Chuang SS. Social capital and individual motivations on knowledge sharing: Participant involvement as a moderator. Inform Manage 2011:48:9-18.

30. Biernacki P, Waldorf D. Snowball sampling problems and techniques of chain referral sampling. Sociol Method Res 1981;10:141-163.

31. Siek KA, Rogers $Y$, Connelly $K H$. Fat finger worries: how older and younger users physically interact with PDAs. In: Costabile M.F, Paternò F. (eds) Human-Computer Interaction - INTERACT 2005. Lecture Notes in Computer Science 2005; vol 3585. Springer, Berlin, Heidelberg.

32. Morita MC, Haddad AE, Araujo ME. Current profile and trends of Brazilian dentists [in Portuguese]. 2010 (1st ed), Maringá (Brazil): Dental Press International. 96p.

33. Shettle C, Mooney G. Monetary incentives in US Government surveys. J Off Stat 1999;15:231-250.

34. Li Y, Xie Y. Is a picture worth a thousand words? An empirical study 
of image content and social media engagement. J Marketing Res 2020;57:1-19.

35. Homola J, Jackson N, Gill J. A measure of survey mode differences. Elect Stud 2016,44:255-274.

36. Kelly B, Margolis M, McCormack L, LeBaron PA, Chowdhury D. What affects people's willingness to participate in qualitative research? An experimental comparison of five incentives. Field Method 2017;29:333-350.

Received February 17, 2021

Accepted March 5, 2021 